\title{
соцИОЛОГИЯ
}

\section{DOI: 10.17805/ggz.2019.5.7}

\section{Поворот к практике: правила, структуры, габитусы}

\author{
E. С. Макаров
}

Российский экономический университет им. Г. В. Плеханова, г. Москва

В статье рассматриваются различные способы конщептуализащии социальных практик в сочиологии в рамках направления, известного как прагматический поворот (practice turn). Сама теория практик представлена как направление, включающее в себя множество подходов со своими особенностями. Уделяется большое внимание связи уровней повседневного взаимодействия (микроуровень) и крупных институциональных структур (макроуровень). Обсуждается проблема следования правилу в контексте соииальных практик.

Ключевые слова: сочиальные практики; следование правилу; прагматический поворот; структурация; дуальность структуры; габитус; символический капитал

\section{Practice Turn: Rules, Structures, Habitus}

E. S. Makarov

Plekhanov Russian University of Economics, Moscow

The article considers different ways of conceptualization of social practices in sociology within a research area known as the practice turn. Practice theory is presented as a trend that includes many approaches with different features. A considerable attention is paid to the relation between the level of everyday interactions (micro level) and the level of big institutional structures (macro level). The problem of following the rule is discussed in the context of the practice turn.

Keywords: social practices; following the rule; practice turn; structuration; duality of structure; habitus; symbolic capital

\section{ВВЕДЕНИЕ}

Поворот к практике является, скорее, широким направлением в социологической мысли, чем конкретной теорией с определенным устоявшимся концептуальным аппаратом. Теоретики этого направления обращаются к практике из-за недостатков объективистских и субъективистских теорий, утверждая, что практика есть «досубъект-объектная» форма социальной жизни и, акцентируя внимание на ней в теоретическом плане, возможно пре- 
одоление картезианского дуализма различения субъекта и объекта. Объективизм склонен к объяснениям с точки зрения макроуровня: и структурализм, и дюргеймианский социологизм, и структурно-функциональный анализ - все эти концепции тяготеют к макроструктурным объяснениям. Субъективизм же, напротив, более подходит для описания микросоциологической проблематики: к примеру, родоначальник социологии повседневности Альфред Щюц являлся сторонником феноменологической социологии, своеобразного синтеза феноменологии Эдмунда Гуссерля и понимающей социологии Макса Вебера. Теоретики практик критикуют обе эти традиции, и некоторые из них предпринимают попытку концептуализации связи микро- и макроуровней. В данной статье обсуждается проблема взаимосвязи двух данных уровней с точки зрения теории практик; анализируются концептуальные способы описания этой связи. Помимо данной проблемы затрагиваются вопросы некоторых свойств социальных практик, в том числе проблема следования правилу; а также предпринимается попытка описания прагматического поворота как целостного направления в социологии.

В социологической теории практики как объект исследования появились примерно в 1970-х гг. За точку отсчета можно условно принять работу Пьера Бурдье 1972 г. «Эскиз теории практик». Две известнейшие работы в рамках прагматического поворота были написаны в 1980 и 1982 гг. — это «Практический смысл» (негласно известен как манифест теории практик) того же Бурдье (Бурдье, 2001) и «Устроение общества» Энтони Гидденса (Гидденс, 2005) соответственно. Также важнейшим направлением прагматического направления в социологии является этнометодология во главе с Гарольдом Гарфинкелем и его исследованиями.

Но истоки внимания социальных исследователей к практикам можно найти уже в работах позднего Людвига Витгенштейна и его последователей, в частности Питера Уинча (Волков, Хархордин, 2008). Идеи Витгенштейна о практическом применении языка, разработанные им в поздние годы своего творчества, обратили внимание исследователей на повседневные языковые практики и контексты этих практик. Сам Витгенштейн такие контексты называл «языковой игрой»: «“Языковой игрой” я буду называть также единое целое: язык и действия, с которыми он переплетен» (Витгенштейн, 1994: 83). В различных контекстах различные языковые практики имеют совершенно разные значения. Не зная логику данной «языковой игры», мы рискуем быть непонятыми, или неправильно понятыми: «Так, фраза “пять плит”, произнесенная на строительной площадке, может функционировать как команда, а не как констатация количества предметов (как это было согласно формальной структуре высказывания)» (Волков, Хархордин, 2008: 18). Определенные контексты или фоны практического применения языка зависят от культуры 
данного сообщества. Ключевое слово здесь — «сообщество». Ведь действительно, кто будет являться гарантом правильного применения практик в определенной ситуации? Для ответа на этот вопрос сначала необходимо определить социальные практики. Это сложно сделать, так как практики являются объектом не только социологии, но и других социальных наук, да и в самой социологии практики концептуализируются по-разному.

\section{ПРАВИЛА}

Не будет серьезным искажением сказать, что практика есть действие по правилу, правилосообразное действие. Однако теперь возникает проблема с определением правила. Одним из главных недостатков объективистских теорий, - тех, в которых описываются объективные структуры, а действия акторов им подчиняются - по мнению теоретиков практик, является именно то, что в них правила описываются как внешние для индивидов предписания. Как отмечает Э. Гидденс, «структура не является чем-то “внешним” по отношению к индивидам: будучи своего рода “отпечатками” в их памяти и проявляясь в социальной практике, она представляется скорее “внутренней”, нежели внешней (как это считал Дюркгейм) по отношению к их деятельности» (Гидденс, 2005: 70). (Структура у Гидденса понимается как правила и ресурсы практики, о чем будет идти речь далее.) Правила имманентны самой практике. Формализованные правила, например, законы, не есть практические правила: мы не всегда соблюдаем формальные правила. Но важнее даже то, каким знанием мы руководствуемся в практике: всегда ли это будет знание самого закона? А если мы собираемся совершить действие, правила которого (в стандартном понимании как нечто объективного) не существует? Вот здесь как раз и проявляется важность сообщества: «Правильность есть не идея правила, выступающая причиной правильного действия, а его (действия) эмпирическое соответствие критерию, носителем которого и выступает данное сообщество» (Волков, Хархордин, 2008: 92). Правила, как и практики, есть коллективные феномены, так как поддерживаются и контролируются коллективом.

Итак, теперь можно сказать, что правило, соответственно которому осуществляется практика, является имманентным практике, а также контролируется сообществом. Но еще одним важным свойством правила является то, что ему можно обучить. Обучение правилу предполагает также прививание акторам практического чувства, т. е. телесных предрасположенностей (такой набор диспозиций П. Бурдье называет габитусом). Научение правилам - важнейшая часть практики: так у актора закладывается телесная предрасположенность к определенным практическим действиям в определенных ситуациях; для одних фонов «правильны» одни практики, и индивиды, усвоив- 
шие это в процессе социализации, «знают» об этом (знают с точки зрения практики; в терминах В.В. Волкова и О.В.Хархордина это есть знание «как» - т. е. знать, как действовать при данном фоне), и уже предрасположены действовать сообразно правилам. Здесь есть два аспекта: во-первых это ограниченность возможного «набора» практик, сообразных правилу в конкретных случаях, а во-вторых - соответствие конкретных практик конкретному фону так, чтобы ситуация оставалась «непроблематичной». Первому аспекту (ограниченности) еще будет уделено внимание, но пока остановимся на втором.

Эксперименты Г. Гарфинкеля (так называемые «гарфинкилинги») как раз и показывали эту «непроблематичность» практик, а точнее то, как она становится «проблематичностью» при несоответствии практик фону. Гарфинкель проводит анализ общения между двумя людьми и выявляет как раз то, что для стороннего наблюдателя, не включенного в практику, сложно, а скорее даже невозможно понять то, о чем идет речь в данном конкретном случае. Это связано как раз с тем самым фоном, задающим правила практики, и благодаря которому практические акторы понимают друг друга. Иными словами, акторы пользуются не логической логикой, а логикой практики, практическими правилами: «Коротко говоря, видимое, но не замечаемое присутствие этих правил используется, чтобы дать людям возможность, не прерываясь, вести общий разговор. Любые отклонения от такого их использования вызывают немедленные попытки восстановить правильное положение дел» (Гарфинкель, 2002: 45).

В одном из экспериментов студенты Г. Гарфинкеля получили задание вести себя около часа в хорошо знакомой им обстановке (в семье, компании друзей) как постояльцы гостиниц: обращаться вежливо, а иногда даже быть чересчур навязчивыми, уточняя значения слов, сказанных в их адрес - короче, вести себя так, как обычно они себя не ведут. В результате в подавляющем большинстве экспериментов поведение студентов определялось как ненормальное, как результат чрезмерной нагрузки на работе, как болезнь и т. д. Что происходило с точки зрения теории практик? Стандартный фон, делающий практики непроблематичными, разрушался, соответственно поведение студентов интерпретировалось как «ненормальное», т. е. разрушающее стандартный ход действий того, как это должно быть. «Реально воспринимаемая участниками ситуация, утратив фон “всем известного”, должна стать “конкретно-бессмысленной”» (там же: 54), т. е. должна появиться неопределенность. Практическое чувство диктует необходимость определенных действий, о которых обычно мы даже не задумываемся: наше тело как будто бы само делает все за нас. Более того, если оно сделает то, что будет интерпре- 
тироваться участниками взаимодействия как «проблематичное» или «ненормальное», разрушится сам рутинный ход повседневной жизни.

До этого момента практики в основном обсуждались с точки зрения микроуровня. Теперь необходимо обратиться к двум наиболее популярным способам концептуализации социальных практик: теории структурации Э. Гидденса и структуралистскому конструктивизму П. Бурдье. Начиная с анализа практик на микроуровне, эти авторы предприняли попытку показать взаимосвязь с макроуровнем (хотя сами они отвергали такую формулировку): их концепции объединяют и макроструктуры, и действия людей в повседневной жизни. Выше шла речь о двух ракурсах практических действий - их ограниченности и соответствии фону. О соответствии было сказано в связи с экспериментами Г. Гарфинкеля, далее речь будет идти в основном об ограниченности.

\section{СТРУКТУРЫ}

П. Бурдье и Э. Гидденс начинают свои работы («Практический смысл» и «Устроение общества») с критики объективизма и субъективизма. «И структурализм, и функционализм решительно подчеркивают превосходство социального целого над его отдельными, индивидуальными элементами» (Гидденс, 2005: 39), в то время как «в концепциях понимающей социологии при объяснении человеческого поведения гармонично лидируют действия и значения; структурные понятия и представления не столь заметны, а принуждение и ограничения практически не обсуждаются» (там же). Теория структурации Гидденса призвана преодолеть концептуальную ограниченность этих направлений, выдвинув на главный план социальной жизни повседневные практики. «Согласно нашей теории, — пишет Гидденс, — предметом социальных наук являются... социальные практики, упорядоченные в пространстве и времени» (там же: 40).

Социальные практики имеют свою временность, которая хорошо схватывается термином Гидденса «поток социальной деятельности». В этом потоке участвуют акторы, обладающие дискурсивным и практическим сознанием, они способны сознательно выстраивать свои стратегии и совершать преднамеренные действия (последствия которых, однако, зачастую являются непреднамеренными). Иными словами, в практической деятельности они руководствуются практическим сознанием, цели и мотивы этой деятельности могут быть выражены дискурсивно (на уровне дискурсивного сознания). Также свою практическую деятельность акторы совершают в соответствии с правилами, о которых было сказано выше. Правила вместе с ресурсами действия образуют (в терминологии теории структурации) «структуру». Структура здесь выступает не как некий каркас, внешний по отношению к челове- 
ческой деятельности, в соответствии с которым эта деятельность осуществляется, а как порождающие эту деятельность правила и ресурсы; правила являются имманентными самому действию, а их знание индивидами составляет практическое знание (знание «как») и может быть выражено на уровне дискурсивного сознания.

Итак, структура у Гидденса — это порождающие практику правила и ресурсы. Регулярно воспроизводимые в пространстве и времени социальные практики образуют социальные системы. Социальные системы обладают структуральными свойствами, то есть институционализированными характеристиками, «зафиксированными» во времени и пространстве. Социальные институты же являются совокупностью наиболее устойчивых и воспроизводимых практик, которые обладают «наибольшей пространственно-временной протяженностью в рамках тех или иных общностей...» (там же: 60). Таков основной концептуальный аппарат теории структурации. Далее постараемся его прояснить, тем самым подойдя к ключевому понятию теории - «дуальность структуры».

Социальные практики, в которые вовлечены индивиды, существуют во времени и пространстве, а наиболее устойчивые их формы образуют социальные институты. Т. е. институты, по Гидденсу, есть «наиболее стабильные черты социальной жизни» (там же: 68), образованные и воспроизводимые повторяющимися практиками. В институтах закреплены те характеристики и значения, которые образуют структуральные свойства социальных систем. Отсюда следует, что структуральные свойства являются результатом практической деятельности акторов. В то же время индивиды руководствуются в своей деятельности практическим сознанием, т. е. знанием правил, составляющих вместе с ресурсами деятельности структуру, которая «проявляется в памяти индивидов в виде “отпечатков” социальной практики...» (там же: 69). Иными словами, практики обладают структуральными свойствами, т. е. иституционализированными характеристиками. Это, в свою очередь, означает, что структуральные свойства являются как ограничителем деятельности (в виде ограничивающих структур), так и ее «продуктом» (как характеристики наиболее устойчивых социальных практик). В этом и заключается идея дуальности структуры: «В соответствии с представлениями о дуальности структуры, структуральные свойства социальной системы выступают и как средства производства социальной жизни и одновременно как результаты, производимые и воспроизводимые этой деятельностью» (там же: 70). Концепция дуальности структуры позволяет увидеть связь институциональных характеристик и практической деятельности индивидов. Другая попытка уловить эту связь принадлежит П. Бурдье, о теории которого далее и пойдет речь. 


\section{ГАБИТУСЫ}

Как пишет П. Бурдье, «чувство игры - продукт опыта игры, а следовательно, объективных структур игрового пространства — это то, что придает игре субъективный смысл, т. е. значимость и смысл существования, а также направление, ориентацию, место, куда должны прийти... ее участники, которые самим своим участием признают ставки игры...» (Бурдье, 2001: 128129). Говоря о чувстве игры, Бурдье имеет в виду то практическое чувство, которым руководствуются акторы, вовлеченные в практику. Для них практика имеет свою логику и темпоральность, они знают «как» им действовать, а иногда их тело само действует за них.

В приведенной выше цитате можно снова увидеть термины, отсылающие к двум линиям, существовавшим в социологической мысли: «объективные структуры» и «субъективный смысл». Первые две главы книги «Практический смысл» посвящены критики объективизма, связанного с именами Клода Леви-Стросса и Фердинанда де Соссюра, и субъективизма в духе экзистенциализма Жана-Поля Сартра. Бурдье считает, что оба этих направления не видят главного - реальные социальные практики. Потому необходимо обратиться к повседневным практикам и практическому смыслу практических акторов, что практики есть «досубъект-объектные» формы жизни и в практическом действии акторы не производят различения на субъект и объект. Объективистские же теории, по Бурдье, склонны к интерпретации действий индивидов через теоретически сконструированные модели; в этом случае теоретики подменяют логичными вещами логику вещей, т. е. логику практик логичной теорией. В том числе это связано с «детемпорализирующим» эффектом науки, которая стремится описать временность практик, этот «поток социальной деятельности» дискретно, например, через структурные элементы. Получается, таким образом, что практическое чувство акторов описывается теоретической моделью. Чтобы не производить такого эффекта, Бурдье предлагает обратить внимание на порождающие принципы практик, которые он называет габитусом: «...габитусы - системы устойчивых и переносимых диспозиций, структурированные структуры, предрасположенные функционировать как структурирующие структуры, т. е. как принципы, порождающие и организующие практики и представления, которые могут быть объективно адаптированными к их цели...» (Бурдье, 2001: 102; курсив источника. - E. M.). Габитус предрасполагает нас к определенным действиям в тех или иных ситуациях, формируя практическое чувство. Акторы могут действовать, исходя из своих установок и стратегий, однако всякие невозможные варианты действий отбрасываются как немыслимые: принципы представления, структурированные габитусом, не дают возможности даже помыслить такие варианты действий. Но сами габитусы структурированы в 
соответствии с объективными структурами данного поля, к тому же они стремятся воспроизводить себя и достаточно невосприимчивы к изменениям. Габитус - это инкорпорированные структуры объективного социального мира, структурирующие субъективный опыт. Сам габитус, «являясь продуктом истории... производит практики как индивидуальные, так и коллективные, а следовательно - саму историю в соответствии со схемами, порожденными историей» (там же: 105). В этом смысле концепция габитуса схожа с дуальностью структуры Э. Гидденса.

Габитусы формируются в соответствии со структурами поля посредством практик обучения. Укоренившиеся модели поведения с раннего детства способствуют принятию мира как реифицированного (т. е. овеществленного), а также возможности действовать в нем в соответствии с предрасположенностями, сформированными габитусом. Важным является то, что соответствие практик их контекстам (что и является основной функцией габитуса) создает условие для формирования мира (языка) здравого смысла, «непосредственная очевидность которого удваивается объективностью, обеспечивающей консенсус в отношении смысла практик и мира...» (там же: 112 ; курсив источника. - E. M.). Для того, чтобы действия одних акторов интерпретировались другими одинаково и были им понятны, необходима синхронизация габитусов, т. е. их однородность в данном поле. В поле с однородными габитусами осуществляется одинаковое кодирование социальных практик. Иными словами, синхронность объективных структур поля и инкорпорированных структур габитуса есть условие формирование одного способа кодирования социальных практик. Говоря о способах кодирования, необходимо понимать особенность его теории (как и теории практик в целом): в ней нет множественных миров, как у А. Щюца, или аутопойетичных социальных систем, как у Н. Лумана; есть только один мир - мир разворачивающихся рутинных, дорефлексивных практик, поэтому социальные коды нужно понимать скорее либо как объективированные институциональные значения, которые опять-таки инкорпорированы в структурах габитуса и были сформированы практиками, либо как категории восприятия и видения социального мира, которые как раз этим габитусом и обусловлены. Данный тезис можно продемонстрировать на замечательном примере самого Бурдье: «Когда кабильская женщина собирает свой ткацкий станок, она не совершает космогонического жеста - она просто собирает ткацкий станок, чтобы ткать на нем ткань, предназначенную для определенной технической цели; но оказывается, что при том символическом багаже, которым она располагает для практического осмысления своей практики - а это прежде всего язык, постоянно отсылающий ее к логике пахоты, - она не может помыслить свои действия иначе как в заколдованной, то есть мистифицированной форме, ко- 
торой так захвачен жадный до вековых тайн спиритуализм» (там же: 188189). Практические акторы, предрасположенные действовать согласно своему габитусу, подчиняются логике практики, однако их восприятие социального мира зависит от их структур видения и разделения, от оппозиций, заложенных в их мышлении, детерминированных, по Бурдье, социальными факторами.

С тем, как и кем навязываются эти оппозиции мышления, связано понятие символического капитала. Согласно Бурдье, капитал функционирует в определенном поле; символическим же капиталом обладают те акторы, которые обладают наибольшим количеством капитала в данном поле. Символический капитал дает им возможность легитимировать структуру распределения капитала в данном поле: к примеру, налоги - это легитимный рэкет, и легитимный потому, что не признается в качестве рэкета (Бурдье, 2016). Акторы, обладающие символическим капиталом, способны создавать практические механизмы легитимации своего положения. Играть в игру с практическим чувством возможно, если вы принимаете ставки и правила игры: навязывание правил и ставок игры и есть главная символическая работа. Символический капитал позволяет обучать правилам практик, формировать габитусы, что является необходимым условием принятия реальности социального мира. Под покровом символического реальное распределение капитала функционирует как «неузнанно-признанное»: неузнанное как таковое, а потому признанное, но также признанное, а поэтому неузнанное. Необходимо отметить, что социальный мир, по Бурдье, состоит из борьбы акторов за капитал, и, далеко не в последнюю очередь, за капитал символический, конвертируемый в другие виды капитала: «Объектом социальной науки является реальность, включающая в себя все виды борьбы - индивидуальной и коллективной, - стремящейся к сохранению или изменению реальности, и в частности такие ее виды, целью которых является навязывание легитимного определения реальности, чья чисто символическая действенность может способствовать сохранению или подрыву сложившегося порядка, т. е. самой реальности» (Бурдье, 2001: 280).

\section{ЗАКЛЮЧЕНИЕ}

В данной статье был проведен анализ основных социологических способов концептуализации социальных практик, а также проблемы взаимосвязи микро- и макроуровней с точки зрения теории практик. Обсуждались основные понятия и их понимание в различных концепциях: правила, структура, практическое чувство, габитус и т. д. Было отмечено, что практика есть правилосообразное действие, а само правило имманентно практике, ему можно обучить, а знание правила составляет практическое знание «как». Практики 
характеризуются соответствием фону и ограниченностью. Э. Гидденс понимает под ограничением структуры и структуральные свойства социальных практик, а П. Бурдье улавливает ограниченность с помощью понятия «габитус». Габитус есть также инкорпорированные в диспозициях акторов структуры поля, таким образом, о нем можно говорить как о связи между макро- и микроуровнями. Гидденс же, в свою очередь, предлагает понятие «дуальность структуры» в качестве описания данной связи: акторы являются «творцами» структур, которые, в свою очередь, ограничивают их действия.

\section{СПИСОК ЛИТЕРАТУРЫ}

Бурдье, П. (2001) Практический смысл / пер. с фр.: А. Т. Бикбов, К. Д. Вознесенская, С. Н. Зенкин, Н. А. Шматко ; отв. ред. пер. и послесл. Н. А. Шматко. СПб. : Алетейя. 562 с.

Бурдье, П. (2016) О государстве: курс лекций в Коллеж де Франс (1989-1992) / ред.-сост. П. Шампань, Р. Ленуар, Ф. Пупо, М.-К. Ривьер ; пер. с фр. Д. Кралечкина, И. Кушнаревой ; предисл. А. Бикбова. М. : Изд. дом «Дело» РАНХиГС. 720 с.

Витгенштейн, Л. (1994) Философские исследования // Витгенштейн Л. Философские работы. Ч. І / пер. с нем. М. С. Козловой, Ю. А. Асеева ; сост., вступ. статья, примеч. М. С. Козловой. М. : Гнозис. 612 с. С. 75-319.

Волков, В. В., Хархордин, О. В. (2008) Теория практик. СПб. : Изд-во Европейского ун-та в Санкт-Петербурге. 298 с. (Сер. «Прагматический поворот», вып. 2).

Гарфинкель, Г. (2002) Исследование привычных оснований повседневных действий // Социологическое обозрение. Т. 2. № 1. С. 42-70.

Гидденс, Э. (2005) Устроение общества: очерк теории структурации / пер. с англ. И. Тюрина. 2-е изд. М. : Академический проект. 528 с.

Дата поступления: 20.10.2019 г.

\section{REFERENCES}

Bourdieu, P. (2001) Prakticheskii smysl [Le Sens pratique / Practical reason] / transl. from French by A. T. Bikbov, K. D. Voznesenskaia, S. N. Zenkin and N. A. Shmatko ; ed. and afterword by N. A. Shmatko. St. Petersburg : Aleteiia Publ. 562 p. (In Russ.).

Bourdieu, P. (2016) O gosudarstve: kurs lektsii v Kollezh de Frans (19891992) [Sur l'État : Cours au Collège de France (1989-1992) / On the state: Lectures at the Collège de France (1989-1992)] / ed. and collected by P. Champagne, R. Lenoir, F. Poupeau and M.-C. Rivière ; transl. from French by D. Kralechkin 
and I. Kushnareva ; foreword by A. Bikbov. Moscow : Delo Publishing House at RANEPA. 720 p. (In Russ.).

Wittgenstein, L. (1994) Filosofskie issledovaniia [Philosophische Untersuchungen / Philosophical investigations]. In: Wittgenstein, L. Filosofskie raboty. Ch. I [Philosophical works. Part I] / transl. from German by M. S. Kozlova and Yu. A. Aseev ; comp., introduction and notes M. S. Kozlova. Moscow : Gnozis Publ. 612 p. Pp. 75-319. (In Russ.).

Volkov, V. V. and Kharkhordin, O. V. (2008) Teoriia praktik [Theory of practices]. St. Petersburg : European University at Saint Petersburg Publ. 298 p. (Series "Pragmaticheskii povorot” / "The practice turn”, issue. 2). (In Russ.).

Garfinkel, H. (2002) Issledovanie privychnykh osnovanii povsednevnykh deistvii [Studies of the routine grounds of everyday activities]. Sotsiologicheskoe obozrenie, vol. 2, no. 1, pp. 42-70. (In Russ.).

Giddens, A. (2005) Ustroenie obshchestva: ocherk teorii strukturatsii [The constitution of society: Outline of the theory of structuration] / transl. from English by I. Tiurin. 2nd edn. Moscow : Akademicheskii proekt Publ. 528 p. (In Russ.).

Submission date: 20.10.2019.

Макаров Егор Сергеевич - студент Российского экономического университета им. Г. В. Плеханова. Адрес: 117997, Россия, г. Москва, Стремянный пер., 28, корп. 1. Тел.: +7 (495) 958-23-27. Эл. адрес: eg.makaraz@mail.ru

Makarov Egor Sergeevich, graduate student, Plekhanov Russian University of Economics. Postal address: Bldg. 1, 28, Stremyannyi Lane, 117997 Moscow, Russian Federation. Tel.: +7 (495) 958-23-27. E-mail: eg.makaraz@mail.ru

Для циитирования:

Макаров E. C. Поворот к практике: правила, структуры, габитусы [Электронный ресурс] // Горизонты гуманитарного знания. 2019. № 5. С. 117-127. URL: http://journals.mosgu.ru/ggz/article/view/1110 (дата обращения: дд.мм.гггг). DOI: 10.17805/ggz.2019.5.7 